\title{
o círculo mágico e a arte de deixar-se repetir na infância: exercitação e aprendizagem nas esferas
}

\author{
alexandre simão freitas ${ }^{1}$ \\ universidade federal de pernambuco, brasil
}

resumo

A inquietude moderna pela formação humana se articulou ao redor de perguntas cruciais pelos exercícios, comportamentos, rotinas, hábitos que são acionados a fim de dar às crianças uma forma determinada, modelando o futuro do infans através de atividades repetidas e reguladas, ao mesmo tempo em que se domestica as forças autoplásticas que interagem na configuração de toda vida. Não casualmente, Peter Sloterdijk apreende a modernidade como uma forma de secularização e coletivização da vida da exercitação, deslocando as asceses transmitidas desde a Antiguidade de seus respectivos contextos espirituais e dissolvendo-as no fluido espumoso das atuais comunidades biopolíticas dedicadas ao treinamento e ao empresariamento da subjetividade. Com base na sua ascetologia é possível perceber como a educação da infância está no centro de uma longa cadeia histórica de adestramentos através de uma arte movida por procedimentos imunológicos e antropotécnicas seletivas voltadas a produção de inúmeras despedidas da infância que visam arrancar o sujeito de suas comunidades insufladas, endurecendo-os e fabricando-os como "atletas do Estado" ou "empresas domésticas". Nessa direção, esse ensaio pretende explorar desde o drama esferológico descrito por Sloterdijk, o que significa pensar a infância quando se tem de pagar o preço da ausência de camadas protetoras, isto é, quando explodem os círculos mágicos, as bolhas de sabão sopradas pelos olhos extasiados da criança.

palavras-chave: antropotécnica; infância; esferologia.

the magic circle and the art of leaving to repeat in childhood: exercising and learning in the spheres

abstract

Modern anxiety about human formation has been articulated around crucial questions for exercises, behaviors, routines, habits that are triggered to give children a certain shape, modeling the future of infans through repeated and regulated activities, at the same time in which the autoplastic forces that interact in the configuration of all life are tame. Not coincidentally, Peter Sloterdijk apprehends modernity as a form of secularization and collectivization of the life of the exercise, displacing the asceses transmitted from Antiquity from its respective spiritual contexts and dissolving them in the foamy fluid of the present biopolitical communities dedicated to the training and the industralism of the subjectivity. Based on his asceticism, it is possible to see how childhood education is at the center of a long historical chain of training through an art driven by immunological procedures and selective antropotechnique turned to the production of innumerable childhood farewells that aim to wrest the subject from their communities insuflated, hardening them and manufacturing them as "state athletes" or "domestic enterprises". In this direction, this essay intends to explore from the spherological drama described by Sloterdijk, which means to think of childhood when one has to pay the price for the

\footnotetext{
${ }^{1}$ E-mail: alexkilaya@uol.com.br
} 
absence of protective layers, that is, when the magic circles explode, the bubbles of soap blown by the eyes the child.

keywords: antropotechnique; childhood; spherology.

\section{el círculo mágico y el arte de dejar repetir en la infancia: ejercitación y aprendizaje en} las esferas

resumen

La inquietud moderna por la formación humana se articuló alrededor de preguntas cruciales por los ejercicios, comportamientos, rutinas, hábitos que se accionan para dar a los niños una forma determinada, modelando el futuro del infans a través de actividades repetidas y reguladas, tiempo en que se domestica las fuerzas autoplásticas que interactúan en la configuración de toda vida. No casualmente, Peter Sloterdijk aprehende la modernidad como una forma de secularización y colectivización de la vida de la ejercitación, desplazando las ascesis transmitidas desde la antigüedad de sus respetados contextos espirituales y disolviendo en el fluido espumoso de las actuales comunidades biopoliticas dedicadas al entrenamiento y al empresariado subjetividad. Con base en su ascetología es posible percibir cómo la educación de la infancia está en el centro de una larga cadena histórica de adiestramientos a través de un arte movido por procedimientos inmunológicos y antropotécnicos selectivos volcados a la producción de innumerables despedidas de la infancia que apuntan a arrancar al sujeto de sus comunidades insufladas, endureciéndolos y fabricándolos como "atletas del Estado" o "empresas domésticas". En esta dirección, este ensayo pretende explorar desde el drama esferológico descrito por Sloterdijk, lo que significa pensar la infancia cuando se tiene que pagar el precio de la ausencia de capas protectoras, es decir, cuando explotan los círculos mágicos, las burbujas de jabón sopladas por los ojos extasiados del niño.

palabras clave: antropotécnica; infancia; esferología. 
o círculo mágico e a arte de deixar-se repetir na infância: exercitação e aprendizagem nas esferas

\section{notas introdutórias}

A problematização da infância no âmbito da reflexão filosófica tem deslocado as imagens historicamente instituídas de criança, incitando-nos a estranhar os conceitos e os discursos sobre uma suposta "natureza infantil" e consequentemente sobre os sentidos imanentes à práxis pedagógica. Mais radicalmente, a infância tornou-se inseparável do nosso esforço para conhecê-la, bem como da linguagem que usamos para descrevê-la (KOAN, 2003; LARROSA, 2004, PAGNI, 2010). Mas vale destacar, nesse movimento de ressignificação filosófica da infância, o papel ocupado pelas reflexões seminais do pensador francês Michel Foucault, sobretudo o uso de sua redefinição da filosofia no contexto das chamadas artes de viver movidas pelo princípio do cuidado de si.

A compreensão foucaultiana da espiritualidade como exercício de autotransformação vem permitindo uma ultrapassagem radical das formas dominantes de governo da infância ${ }^{2}$. Nos termos de Pedro Pagni (2010, p.114), os trabalhos tardios de Foucault possibilitaram que a infância se tornasse um acontecimento que se "interpõe entre a experiência e a linguagem constitutiva da história e formadora do espírito", reformulando nossa compreensão acerca de uma possível pedagogia da infância, ao retomar aquilo que se esqueceu, desde a modernidade, a saber: a infância como condição e possibilidade da própria experiência do pensar. Mais concretamente, sua noção de espiritualidade corrigiu o foco analítico dos olhares dirigidos às crianças ao fazer da infância um modo próprio de contestação da cultura educacional hegemônica.

Por outro lado, a obrigatoriedade do ingresso das crianças de seis anos no sistema formal de ensino, em função da Lei 11.274/2006, vem produzindo uma mudança não apenas nos currículos, mas na própria cultura escolar, a fim de

\footnotetext{
2 Embora Foucault não tenha desenvolvido uma teoria da infância ou uma formulação conceitual sistemática sobre esse tema, inúmeros pesquisadores têm se apoiado em suas ferramentas analíticas a fim de interrogar os modos de construção da infância, a invenção do sujeito infantil e os dispositivos disciplinares presentes nas instituições (Cf. REZENDE, 2015).
} 
considerar a inclusão de outros saberes e outras práticas formativas. Situação que, para alguns, talvez signifique que chegou o tempo longamente desejado de aprendermos com as próprias crianças o que a infância tem a nos dizer (PASSINI; MARIN, 2011). Mas que, para outros, indica o risco concreto de fazer a criança tornar-se aluno, obstruindo a peculiaridade própria da infância (SANTOS; BOLZAN, 2008, p. 613), mediante uma "racionalidade escolar" que não pode não "engolir" os sentidos formativos dos projetos pedagógicas voltados às crianças.

Permanece, contudo, a conviç̧ão de que a infância se configura como uma categoria vital para repensar os sentidos da formação humana no presente. Pois, enquanto uma forma de experiência que manifesta um tempo em que o mundo pode ser reconstruído, a infância se constitui como um intercessor capaz de mover uma crítica radical às teorias filosóficas e educacionais, servindo inclusive para desmascarar o processo de expropriação da experiência infantil por uma razão de estado intimamente articulada ao projeto da racionalidade moderna que, como sabemos, nasce de uma desconfiança sistemática acerca da experiência encarnada no sujeito infantil ${ }^{3}$.

Giorgio Agamben (2005, p. 59), dentre outros, tem nos recordado que infans remete a um não-saber, a uma não-fala, fazendo do reconhecimento dessa negatividade constitutiva da infância não "simplesmente algo que precede cronologicamente a linguagem e que, a uma certa altura, cessa de existir", mas algo que "constitui-se aliás ela mesma na expropriação que a linguagem dela efetua, produzindo a cada vez o homem como sujeito". Infância, experiência e linguagem são fenômenos enredados, coexistentes em sua historicidade, ponto de convergência e de disputas no jogo da antropogênese.

Paradoxalmente, no entanto, uma das consequências forcluídas no tratamento desse posicionamento é a percepção de que as crianças expressariam, elas mesmas, uma linguagem própria, mediante modos próprios de significação do mundo. O que significa dizer que as culturas da infância transportam consigo as

\footnotetext{
${ }^{3}$ Exemplar, nesse exercício, é a postura do pensador italiano Giorgio Agamben que, no ensaio Infância e História. Ensaio sobre a destruição da experiência (2005), elabora uma curiosa relação entre a experiência e a infância como caminho de pensamento privilegiado da análise da antropogênese histórica.
} 
marcas do tempo, exprimindo a sociedade em todas as suas contradições. E por isso mesmo quando se considera a existência de uma colonização utilitária do imaginário infantil, também não se pode ignorar que há "resistência a essa colonização, através das interpretações singulares, criativas e frequentemente críticas que as crianças fazem" (SARMENTO, 2000, p. 16).

Nesse contexto, a presente reflexão segue a direção indicada por Kohan (2003) quando este afirma que a infância convoca os conceitos da Filosofia e da Educação a se reinventarem, liberando novos modos de vida, novos modos de pensar. O argumento central, por sua vez, acompanha alguns rastros deixados pela ascetologia do filósofo alemão Peter Sloterdijk, defendendo que a educação está no centro de uma longa cadeia histórica de adestramentos que visa o aperfeiçoamento do homem através da arte sutil de produzir despedidas regulares e continuadas da infância. $\mathrm{O}$ chamado à exercitação cumpre um mandato: é preciso modelar o infans, domesticando suas forças autoplásticas.

Logo, a infância surge inseparável de uma arte sutil dos exercícios, acionando um conjunto de rotinas e hábitos que pretendem adequar as crianças a uma forma cultural determinada. Na atualidade, essa arte movida por meio de incubadoras, procedimentos imunológicos e antropotécnicas seletivas visa arrancar o sujeito de suas comunidades insufladas, endurecendo-os e fabricandoos como atletas do Estado ou empresas domésticas. Assim, essas reflexões especulativas almejam pensar a infância quando se tem de pagar o preço da ausência de camadas protetoras, isto é, quando explodem os círculos mágicos, as bolhas de sabão sopradas pelos olhos extasiados da criança, explorando contribuições da filosofia esferológica de Sloterdojk com as catástrofes ou a iminência de catástrofes que se anunciam em toda experiência da infância.

\section{o exercício de humanização da infância nas fazendas de domesticação do estado}

Um dos principais obstáculos para pensar de outros modos a infância está arraigado justamente na linguagem que mobilizamos para lidar com ela. Ainda mais que o discurso filosófico-educacional se apresenta como um espaço de controle dessa mesma linguagem. A modernidade filosófica, por exemplo, 
construiu e difundiu a percepção reiterada de que a escola seria o lugar natural de realização e desenvolvimento da infância. Um lugar especial nascido não propriamente para ensinar, mas antes de tudo para que a infância possa ocorrer. Uma narrativa que é devedora de um determinado arbítrio cultural, o humanismo e suas influências desembrutecedoras (SLOTERDIJK, 2000) ${ }^{4}$.

Como resultado, a infância permanece sendo algo que nossos saberes, nossas práticas e nossas instituições buscam capturar, explicar, nomear e governar. Mais: a modernidade constituiu a infância como um dos objetos privilegiados do desejo do desejo de Estado, concebido aqui como uma espécie de "habitáculo", um domus, uma fazenda de domesticação, cuja função, nesse caso, consiste em expor a infância à cisão fundante entre o político e o doméstico. A origem dessa cisão, como sabemos, remonta à Grécia arcaica, e produziu um esquema cosmológico tão potente que as instituições ocidentais daí derivadas, como a filosofia ou a escola, ou estão presas por uma certa miopia conceitual em relação aos seus propósitos, ou bem desejam acreditar que são universais e, por isso mesmo inexoráveis ou, possivelmente, ambos (LEIRNER, 2012).

Na longa duração, o conceito de domesticação, contudo, foi jogado para um plano politicamente irrelevante, obliterando com isso a presença da infância no espaço da polis ${ }^{5}$. Nos termos de Deleuze e Guattari (1997, p. 119), o estado sempre esteve aí, assim como tudo aquilo que vai contra ele, nisso mesmo que chamamos de domesticação. Toda política é doméstica, uma vez que o estado é fundamentalmente movimento de interiorização do domus e da soberania. No entanto, a soberania só reina sobre aquilo que é capaz de interiorizar, de apropriar-se. Este processo de interiorização, por sua vez, funciona como uma espécie de captura mágica uma vez que ela aparece sempre como já feita e se

\footnotetext{
4 Nos termos de Sloterdijk (2000), o trabalho pungente das escolas do humanismo reside fundamentalmente na domesticação da "bestialidade do homem", por meio da leitura edificante dos clássicos (p. 13).

${ }^{5}$ Contudo, desde $O$ Político e A República, correm pelo mundo discursos que falam da comunidade humana como um parque zoológico que é ao mesmo tempo um parque temático; a partir de então, a manutenção de seres humanos em parques ou cidades surge como uma tarefa zoopolítica (SLOTERDIJK, 2000, p. 48-49). O que pode parecer um pensamento sobre a política é, na verdade, uma reflexão basilar sobre regras para a administração de parques humanos ou como preferimos de fazendas de domesticação (LEIRNER, 2012).
} 
pressupondo a si mesma. Mais: a captura inclui, em si mesma, múltiplos processos: disciplinarização, hierarquização, dispositivos e agenciamentos ${ }^{6}$.

Não casualmente, Sloterdijk (2000, p. 13-14) compreende a reunião dos homens reunidos nas cidades como o produto mais genuíno de uma antropodiceia, por meio da qual a humanidade busca se fortalecer frente à bestialidade e suas correspondentes mídias desinibidoras. O problema é que, com a decadência do humanismo, torna-se cada vez mais difícil "atar os laços telecomunicativos entre os habitantes" das cidades.

Lembremos que um dos vetores do "credo humanista" é justamente a convicção de que os seres humanos são "animais influenciáveis" e de que é imperativo prover-lhes o "tipo certo de influências" (SLOTERDIJK, 2000, p. 17). Humanos são, portanto, todos aqueles capazes de fazer uma escolha, melhor dizendo, eles não são nada mais do que essa escolha. O que se esquece, muitas vezes, é que essa escolha possui um direcionamento político específico. Na Antiguidade, esse direcionamento visava à recusa do teatro (arena) e à aceitação da leitura. Na época contemporânea, porém, quando a leitura deixou de cumprir seu papel humanizante, desdobra-se uma disputa pelo humano entre mídias desinibidoras e mídias domesticadoras. Uma das fontes do conflito situa-se na passagem, preferimos dizer indistinção, dos processos de domesticação do nível pedagógico para o nível ontológico. Fenômeno provocado pela prevalência dos processos de governamentalização, liberal e neoliberal, destravados pela biopolítica.

Esses processos de agenciamento da vida acabam por produzir monstruosos deslocamentos e rejeições em massa, que recolocam em questão todo o processo de fundamento da domesticação e da formação do homem tornada anacrônica. Daí,

[...] a questão da época: o que ainda domestica o homem, se o humanismo naufragou como escola da domesticação humana? $\mathrm{O}$ que domestica o homem, se seus esforços de autodomesticação até

\footnotetext{
${ }^{6}$ Obviamente, nada disso elide a possibilidade de uma volta ao exterior. Pois, assim como o estado domestica o animal ou coisa ou gente, esta(s) introduz nele um vetor de potência, fazendo da domesticação uma operação arriscada já que se trata de uma processo sempre em aberto.
} 
agora só conduziram, no fundo, à sua tomada de poder sobre todos os seres? O que domestica o homem, se em todas as experiências prévias com a educação do gênero humano permaneceu obscuro quem - ou o quê - educa os educadores, e para quê? Ou será que a questão sobre o cuidado e formação do ser humano não se deixa mais formular de modo pertinente no campo das meras teorias da domesticação e educação? (SLOTEDIJK, 2000, p.32)

A percepção de Sloterdijk é que os atuais modos de uso da técnica alteraram os processos de domesticação do humano, deslocando o projeto humanista e fazendo com que, no limite, esse projeto e o tipo de domesticação que ele propõe naufragassem não importando "as mudanças de rumo" adotadas pelas mais variadas tentativas de manter e sustentar a pastoral filosófico-pedagógica do humanismo. Pouco importa, ele nos diz:

[...] o discurso sobre a diferença e a relação entre domesticação e criação, e qualquer referência à aurora de uma consciência quanto à produção de seres humanos e, de maneira mais ampla, de antropotécnicas - isto são processos dos quais o pensamento atual não pode desviar os olhos, a menos que se queira, novamente, aceder à suposição de inocuidade. É provável que Nietzsche tenha ido um pouco longe demais ao propalar a sugestão de que a transformação do homem em animal doméstico foi o trabalho premeditado de uma associação pastoril de criadores, isto é, um projeto do clero, do instinto paulino que fareja tudo o que no homem poderia resultar em voluntariedade $\mathrm{e}$ autonomia e contra o qual imediatamente faz uso de métodos de apartação e mutilação (SLOTERDIJK, 2000, p. 42).

Os elementos que compõem um discurso sobre o humano, e consequentemente sobre sua infância, devem, doravante, levar em conta os processos denunciados por Nietzsche. A formação humana permanece assim no centro de uma longa cadeia histórica de adestramentos que visa o aperfeiçoamento do homem através da arte de produzir despedidas continuadas da infância. O chamado à exercitação cumpre então um mandato moral: é preciso modelar o infans, domesticando suas forças autoplásticas.

\footnotetext{
7 A resposta a esses questionamentos encontra seu espaço dentro da biopolítica enquanto regulamentação do poder sobre a vida (Foucault) e enquanto dispositivo que tem como base a vida nua (Agamben). Todavia, Sloterdijk não se ocupa em tematizar especificamente o processo político que vige sobre a vida, mantendo-se em parâmetros analíticos estritamente ontoantropológicos.
} 
Sob esse propósito, o processo de domesticação carrega implicitamente uma concepção específica sobre os sentidos da infância. Do ponto de vista antropotécnico, a infância configura-se como o ponto modal da articulação de deferentes técnicas que regem o modo de lidar com o humano com vista a amansá-lo ou docilizá-lo. Considerada uma matriz de integibilidade do humano, a escolarização da infância, por sua vez, assume aqui um papel chave no que se refere ao poder de decisão no próprio processo biopolítico de seleção. Ainda mais que a modernidade, como uma forma radical de secularização e coletivização da vida da exercitação, deslocou as asceses transmitidas desde a Antiguidade de seus respectivos contextos espirituais, dissolvendo-as no fluido espumoso das atuais comunidades biopolíticas dedicadas ao treinamento e ao empresariamento.

Como resultado, a infância surge inseparável de uma arte dos exercícios, acionando um conjunto de rotinas e hábitos que pretendem adequar as crianças a uma forma cultural altamente mercantilizada. Uma arte movida por meio de incubadoras, procedimentos imunológicos e antropotécnicas que visam fazer nascer os sujeitos, endurecendo-os e fabricando-os como atletas do Estado ou empresas domésticas.

Nesse cenário, a educação da infância é convidada também a tornar-se terapêutica e medicalizante, criando este "direito novo": aquele dos indivíduos despojados da capacidade de intervirem em suas próprias vidas, subjetivados justamente "como infantis e incapacitados, em risco e em débito com aprendizagem e desenvolvimento com vistas à cidadania e à autonomia" (LEMOS, GALINDO, NASCIMENTO, 2016, p. 12). Reduzida à condição de um esforço gestionário das subjetividades, a educação da infância passa a funcionar, de direito e de fato, como "empresa para o desenvolvimento humano e formação gerencial dos comportamentos, afetos, relações e crenças".

Garantir direitos é analisado pelo crivo de uma educação baseada em competências e habilidades de cuidado parental para o ensino do acesso às oportunidades de crescimento e desenvolvimento humano, de acordo com as premissas normalizadas e normatizadas do que tem sido designado pelos especialistas como proteção e defesa social (LEMOS, GALINDO, NASCIMENTO, 2016, p. 15). 
Na mesma direção, Araújo (2004) enfatiza que essa nova ascese empreendedora articula, simultaneamente, políticas públicas e iniciativas privadas do campo educacional, aproximadas pela noção de governar-se pela lógica de vida empreendedora enquanto valor modelador das competências e habilidades associadas aos processos de desenvolvimento afetivo e social em nome de um empoderamento produtivo e dócil.

Os riscos pagos por quem tenta escapar dessa racionalidade empreendedora são antecipados e permanentemente regulados pelas políticas de segurança, com maior intensidade de disciplinamento das condutas e de regulação da vida dos grupos desobedientes, indóceis à normalização do mercado neoliberal ${ }^{8}$. De todo modo,

[...] em nosso presente, em termos amplos, tanto o governo como o controle das subjetividades e das condutas infantis, seja das referentes à infância pobre (infância excluída), seja das referentes à infância de origem pequeno-burguesa, característica das classes média e média-alta dos países desenvolvidos e emergentes (infância incluída), são efetuados mediante a estratégia de um empresariamento generalizado da sociedade e da educação. As sociedades contemporâneas, animadas por um novo capitalismo, de tipo conexionista, transnacional e financeiro, assumem uma dupla face, expressando-se simultaneamente como sociedades de controle (cf. Deleuze, 1992) e como sociedades-empresa (cf. Foucault, 2008). Por um lado, o controle e o governo das condutas dos indivíduos dão-se cada vez mais por intermédio de um empresariamento da sociedade; por outro, o empresariamento das subjetividades e das relações sociais constitui como que a via privilegiada para o controle e o governo das condutas. Assim, em termos amplos, podemos pensar o governo das infâncias em nosso presente como estando estreitamente relacionado ao empresariamento da sociedade, da educação e dos demais processos implicados à produção de subjetividades infantis [modos de construção do que seria "ser criança"] (GADELHA, 2013, p. 218).

\footnotetext{
${ }^{8}$ A captura desses grupos resistentes se tornou o próprio "negócio do social", voltado à tutela dos "grupos subalternizados e memorizados em suas possibilidades de governar-se" no contexto da chamada gestão social de riscos, que apresenta como solução ensinar esses grupos a "gerir-se, mas pela lógica empresarial no chamado empoderamento e na capitalização dos afetos, das crenças e relações sociais que os mesmos venham a realizar. Todas as práticas passam a ser pensadas como oportunidades para negócios e investimentos lucrativos ou potencialmente de sê-lo em algum momento social (LEMOS, GALINDO, NASCIMENTO, 2016, p. 13).
} 
Mas, sem dúvidas, o mais curioso "nos saberes e valores que sustentam e animam essas novas práticas e pedagogias", lembra Silvio Gadelha (2012, p. 231), refere-se ao modo "como se referem "à" infância e buscam atende-la". Nesse cenário,

[...] tudo se passa como se - após um estranho sono sócioantropológico e/ou psicossociológico - de repente, se dessem conta de que estavam como que surdos e/ ou indiferentes ante aos anseios, às expectativas, aos desejos, às percepções e às falas das crianças - como se nunca as tivessem coagido a falar de si, de seus desejos, medos, "pecados", culpas e "erros", mas também de seus irmãos, de seus pais, professores etc.). Talvez isso explique a mobilização geral em torno do novo imperativo: “É preciso escutar e dar voz às crianças"! (GADELHA, 2013, p. 231)

Assim, tanto a "escuta da infância" como o "dar voz às crianças", exigem a proliferação de técnicas específicas, uma parafernália de exercícios sistemáticos e determinados, forjando uma nova arte de governamento que não visa domesticar e/ou adestrar disciplinarmente e tampouco requer mecanismos da normalização ancorados, em sentido estrito, na exclusão do não- normalizável. Deparamo-nos, antes de tudo, com o que Foucault (2008, p. 354-355) chamou de uma espécie de "otimização dos sistemas de diferença", permitindo que os exercícios modeladores da infância deixem uma área livre "para os processos oscilatórios, em que haveria uma tolerância concedida aos indivíduos e às práticas minoritárias". Pois, isso permite uma ação, "não sobre os jogadores do jogo, mas sobre as regras do jogo", ou seja, uma intervenção que não é do tipo da "sujeição interna dos indivíduos, mas uma intervenção de tipo ambiental".

Nos termos de Sloterdijk (2012, p. 14), trata-se de um renascimento do ideal atlético agora ancorado em "asceses desespiritualizadas", as únicas capazes de responder aos valores orientadores da vida depois do crepúsculo dos deuses. A "desespiritualização da ascese", portanto, ao contrário do que pensava Nietezsche não precisa recair em niilismo. A desespiritualização indica apenas o outro lado da informalização da espiritualidade crescentemente privatizada ${ }^{9}$. Nesse novo

\footnotetext{
9 Para Sloterdijk, o evento principal dos tempos modernos não é a secularização, mas a desradicalização da diferença ética com sua desverticalização da existência. "Nós tínhamos que esperar até o mono-humanismo, para vivenciar, como as sementes híbridas do monoteísmo vingavam" (SLOTERDIJK, 2012, p. 199).
} 
cenário, além de exercitar novas habilidades, os sujeitos podem inclusive exercitar não fazer exercícios direcionados.

A vitalidade, entendida somaticamente e espiritualmente, é mesmo o meio que contém um desnível entre o mais e o menos. Ela tem dentro de si o movimento vertical que orienta as subidas, ela não precisa adicionalmente atratores externos e metafísicos. Que Deus deve estar morto, neste contexto, não importa. Com ou sem Deus cada um chega somente tão longe quanto a sua forma permite (SLOTERDIJK, 2012, p. 67).

A ascese atlética presente em nosso tempo busca, antes de tudo, responder às intermináveis demandas por investimentos em si mesmo. A ideia central a ser retida aqui é a conquista do improvável, com a ressalva de tom marcadamente foucaultiano de que "os homens não são, nas suas demandas de liberdade e autodeterminação, reprimidos pelas disciplinas, regimes e jogos de poder, mas, possibilitados" (SLOTERDIJK, 2012, p. 241). Nesses termos, governa-se a infância, em nossa atualidade, fazendo com que o impossível torne-se, ele mesmo, um imperativo incontornável da sua formação.

O tensionamento vertical, assim constituído, além de estabelecer uma hierarquia entre valores, sem as quais qualquer ética se evapora, convoca as escolas a desdobrar toda uma ortopedia formadora das próprias crianças, destravando ou desinibindo uma forma de "personalidade" interessada na melhoria permanente da sua própria performance.

No decorrer do processo de esclarecimento antropológico torna-se nítido o grau elevado de exigência envolvido e os efeitos onto-político-antropológicos daí decorrentes. O próprio ser-aí passa a se confundir com a atualização individual de chances de habilidades e performances, o que exige que cada um se movimente desde sempre em uma escala móvel na qual o próprio sujeito deve se reposicionar, de modo contínuo, com base nos resultados de seus esforços, sem que ele possa acusar ou desqualificar os primeiros colocados como repressores (SLOTERDIJK, 2012, p. 515).

Com isso, as práticas de educação da infância deixam de se ocultar sob os nomes da arte, da formação e mesmo do trabalho. Somente no atletismo contemporâneo, a infância assume-se como uma prática ascética em si mesma. 
Aqui não há mais engano: educar a infância significa treiná-la para o auto empreendimento, ou para ser mais exato para faze-la um empreendimento de si mesma, fazer de si mesma um empreendimento empresarial ${ }^{10}$, entrecruzando duas antropotécnicas conflitantes entre si.

Por um lado, a criança precisa deixar-se operar: deixar-se-informar, deixar-sedivertir, deixar-se-servir, deixar-se-curar, deixar-se-transportar e assim por diante, a pedagogia atuando na modalidade da autotransformação passiva. Por outro lado, contra a passividade e a serenidade, que deixa "ser o que é" e coloca, no caso extremo, o corpo da criança à disposição das mais variadas operações educativas, levantam-se as vozes militantes e ativistas dos pedagogos que exigem que a própria criança se coloque como sujeito de todo processo, operando ela mesma as transformações que deseja.

Tropeçamos aqui nos conflitos insolúveis que atravessam os debates sobre a formação humana, em geral, e sobre a formação da infância, em particular. Contudo, há um vetor frequentemente ignorado: o que significa pensar a educação da infância quando se tem de pagar o preço da ausência de camadas protetoras, isto é, quando explodem os círculos mágicos, as bolhas de sabão sopradas pelos olhos extasiados da criança?

Essa pergunta aparentemente ininteligível exprime, como veremos, o círculo vicioso com que as teorias filosófico-educacionais têm se debruçado sobre a infância, bem como a impotência revelada nas dificuldades para pensar saídas ao atual contexto biopolítico em que proliferam as práticas de si empresariais e atléticas.

Vimos com Agamben, a indissociabilidade entre a experiência da infância e a experiência da linguagem. Para Sloterdijk (2016, p. 353), contudo, "toda a linguagem é [também] uma música da separação", uma espécie de louvor ao parceiro perdido, uma nostalgia da relação pura. É em torno do eterno drama de

10 O imperativo metanoético,"Você tem que mudar sua vida!", ganha dessa maneira um crescente significado político. Sloterdijk (2012, p. 527) distingue consequentemente entre a modalidade forte e a modalidade fraca do imperativo metanoético. A modalidade fraca coloca o indivíduo numa posição de semipassividade, na qual sofre as consequências de manipulações e operações de fora para dentro; o indivíduo deixa-se operar. Enquanto na modalidade forte o próprio indivíduo se opera. 
separação diante da condição primordial de coexistência que gira a filosofia esferológica de Sloterdijk ${ }^{11}$, para quem existe um elo que, perdido no nascimento do indivíduo, embasa toda a existência humana. Talvez, aqui, nessa contra intuição possa repousar um outro pensamento da infância.

\section{educar nas bolhas: o drama da infância para além dos círculos mágicos}

Tendo recebido seu presente, a criança se debruça febrilmente sobre a sacada e acompanha com os olhos as bolhas de sabão que sopra para o céu através da pequena argola diante de sua boca. Primeiro, um enxame de bolhinhas jorra para o alto, na caótica alegria de cintilantes bolas de gude azuis lançadas ao léu. Depois, na próxima tentativa, um balão oval maior desprende-se tremulante da argola, cheio de uma vida receosa, e é levado pela brisa, planando em direção à rua logo abaixo. Segue-o a esperança da criança extasiada. É ela própria que desliza com sua bolha mágica no espaço exterior, como se, por alguns segundos, seu destino estivesse ligado ao daquela ansiosa criação. Quando, após um voo oscilante e prologando, a bolha finalmente rebenta, o artífice da bolha de sabão deixa escapar, do alto da sacada, um som que é ao mesmo tempo um suspiro e uma exclamação de júbilo. Durante o tempo de vida da bolha, seu insuflador esteve fora de si, como se a subsistência daquela bola dependesse de permanecer envolvida por uma atenção de que desliza junto com ela [...]. O jogo se prolonga incansavelmente; de novo deslizam as bolhas do alto, e de novo o insuflador está apaixonado por elas, como se fossem milagres autoconsumados [...]. A atenção do pequeno mágico voa para longe em seu encalço e sustenta as finas paredes dos corpos insuflados com sua entusiástica assistência. Entre a bolha de sabão e o seu insuflador vigora uma solidariedade que ignora o resto do mundo. [...] No êxtase da atenção, a consciência infantil separa-se, por assim dizer, de sua fonte corporal. Se, em outras ocasiões, o ar expirado se perde sem deixar traços, o sopro encerrado na bolha adquire uma sobrevida momentânea. Enquanto as bolhas se movimentam no espaço, seu autor está verdadeiramente fora de si - ao lado delas e no interior delas. Assim, a bolha de sabão se torna, para seu autor, o meio para uma surpreendente expansão anímica (SLOTERDIJK, 2016, p. 19).

É com essa narrativa poética que Sloterdijk introduz seus leitores no primeiro volume da sua trilogia Esferas, denominada Bolhas. Trata-se da descrição de uma gravura a meia tinta de uma criança brincando de fabricar bolhas de sabão

\footnotetext{
${ }^{11}$ Lançado em 1998, o primeiro volume de sua trilogia Esferas: bolhas, publicado pela editora alemã Suhrkamp e, no segundo semestre de 2016, em sua edição brasileira pela Estação Liberdade.
} 
de Sir John Everett Millais (1829-1896), que ilustra o frontispício da sua obra. A imagem figura no lugar de uma crítica radical ao pensamento da modernidade e sua virada antropotécnica.

A criança que brinca de insuflar suas bolhas de sabão, coexistindo com elas "em um campo tensionado pela simpatia atenta" e seguindo-as "no espaço aberto" está em contradição flagrante, diz Sloterdijk (2016, p. 20), com “o sujeito cartesiano aferrado a seu locus pensante sem extensão, a observar uma coisa extensa em sua trajetória". Ao contrário deste, o infante jogador-experimentador de Sloterdijk se projeta magicamente no espaço, transformando "a região entre o olho e o objeto em uma esfera animada". Contudo, mal sabe ela que, a criança que brinca, ao ser introduzida aos afazeres escolares, aprenderá, melhor dizendo, desaprenderá a lição oculta em seu próprio fazer infantil:

[...] que o espírito, a seu modo, está ele próprio no espaço. Ou não se deveria antes dizer que aquilo que outrora se chamava espírito já designava, desde o início, comunidades especiais aladas? Para quem já fez as primeiras concessões a tais pressentimentos, parece razoável prosseguir perguntando na mesma direção: se a criança insuflou seu alento nas bolhas de sabão e permanece fiel a elas com seu olhar extático - quem, então, colocou seu alento na criança que brinca? Quem se mantém fiel à criança em seu êxodo para fora do seu quarto de brinquedos? Quem acompanha a criança em seu caminho para as coisas e para o que há de essencial nelas: o mundo compartilhado? (SLOTERDIJK, 2016, p. 21).

As questões abertas por Sloterdijk (2016) são inquietantes, sobretudo para aqueles que, herdeiros das promessas da modernidade, creem que o humano se dá, de pronto, como um sujeito individual, independente e totalmente autônomo, e não como o resultado de uma partilha original, enquanto ser-imerso-em-ummundo, um ser-em-esferas ${ }^{12}$. Para ele, viver, constituir esferas e pensar são nomes diversos para uma mesma experiência: a de que a vida é uma questão de forma, e que, "por toda parte onde existe a vida humana, seja ela nômade, seja sedentária,

\footnotetext{
${ }^{12}$ Com o conceito de esfera, Sloterdijk propõe uma teoria híbrida - ao mesmo tempo, filosófica, literária, psicanalítica, sociológica, antropológica - sobre a imersão do humano em ambientes imunológicos novos diante da perda do habitat originário e da expulsão concomitante para um exterior desprotegido (PITTA, 2017, p. 49). Uma especulação original sobre como sobrevive e se protege o humano, animal que deixou de possuir habitat para se aventurar na excentricidade da existência.
} 
surgem bolhas habitadas" (p. 14). A esfera é uma espécie de "rotundidade fechada", embora dotada de um interior partilhável e habitável.

Como habitar significa sempre construir esferas, menores ou maiores, os homens são as criaturas que estabelecem mundos circulares e olham em direção ao exterior, ao horizonte. Viver em esferas significa produzir a dimensão na qual os homens podem estar contidos. Esferas são criações espaciais imunologicamente efetivas para seres extáticos sobre os quais opera o exterior (SLOTERDIJK, 2016, p. 29).

A esferologia configura-se, portanto, como uma teoria inspirada de receptáculos imunológicos, e por meio dela Sloterdijk pretende resolver a questão, cada vez mais urgente, do onde do homem: onde estamos quando estamos no mundo?

Isso porque com a morte de Deus, a grande esfera protetora da civilização humanista vê dissolvidas suas relações protetoras de intimidade em relações cinzentas e anestésicas ${ }^{13}$. Em outros termos, com o processo de globalização, desde a descoberta das Américas em 1492 e das inovações tecnológicas no século XIX e XX, desenha-se um cenário de alta movimentação cinésica capaz de ameaçar a sobrevivência da sociedade humana, cada vez mais fragmentada e com seus respectivos fragmentos em rota de colisão. Uma catástrofe de desintegração seria o outro lado da globalização que culminaria num ponto temporal não definível, num crash de dimensões planetárias.

A conclusão dessa situação só pode ser uma. Os homens têm que partir para um novo ciclo de lutas dos seus sistemas imunológicos, dessa vez não simplesmente para defender o próprio organismo ou para proteger outros fragmentos compostos por famílias, amigos, tribos ou nações. A imunologia geral

\footnotetext{
13 Sistemas imunológicos são expectativas de danificação e violação, somatizados ou institucionalizados, que se baseiam na distinção entre o próprio e o estranho (SLOTERDIJK, 2009, p. 709). A filosofia reconhece o sistema imunológico apenas no nível do organismo biológico individual. Sloterdijk, contudo, identifica mais dois sistemas imunológicos: um sistema imunológico social que garante, quando funciona, segurança jurídica, prevenção social e sentimentos de pertencimento; e um sistema imunológico simbólico que garante a validez das normas intergeracionais, compensa a certeza da morte individual e estabiliza a imagem do mundo. Todos esses sistemas imunológicos podem passar por crises e superá-las, assim como podem fracassar plenamente, o que significa morte individual ou morte coletiva.
} 
exige transcender qualquer diferenciação usual do próprio e do estranho, no horizonte de asceses que cooperem universalmente.

O problema, facilmente constatável, é que essa situação exige codificar novas antropotécnicas que sejam adequadas à existência em um contexto onde coabitem todos os contextos. Eis o ponto vital do argumento: existir em um mundo qualquer é, antes de tudo, habitar uma comunidade de cuidado, numa relação de proximidade situada, uma esfera coletivamente partilhada de animação e proteção. Só assim, os sujeitos que habitam essa espécie de bolha mágica são reconhecíveis como sujeitos e suas vidas garantidas ${ }^{14}$.

Para tanto, Sloterdijk defende que todas as formas de vida estão atravessadas de encantamento magnetopático e de ressonâncias de proximidade, e que só, na modernidade, com a calcificação do individualismo, passaram a ser pensadas pelo filtro reducionista da consciência pensante e da autonomia do sujeito individualizado. Assim,

O que chamamos tornar-se adulto são essas trabalhosas passagens de subjetividades em menor escala para formas do mundo mais ampliadas; a expressão também muitas vezes significa a adaptação da consciência tribal a condições imperiais e fundadas na escrita. Para a criança que fomos, o espaço de operações ampliado pode, ainda por um tempo, denominar-se grande família; tão logo esse horizonte é ultrapassado, as formas sociais fazem valer suas pretensões de moldar e animar os indivíduos (SLOTERDIJK, 2016, p. 54).

O seu ponto de partida é sempre uma relação diádica íntima, cujos polos, em ressonância e imbricação mútua, se diferem e se tencionam no próprio espaço relacional. Para ele, as relações pré-natais de todo infante são uma prova viva desse estado que recebe o nome sugestivo de intimidade.

Intimidade - é com essa palavra maltratada que iremos abordar os mistérios da loucura topográfica humana, pois não dispomos de

\footnotetext{
${ }^{14}$ Aqui, vale ressaltar, a esferologia de Sloterdijk beira uma espécie de antropofagia mística, cujo objetivo é explorar casos extremos de imersão, no qual se destitui qualquer distanciamento entre os habitantes de uma relação. Ele parte da crença religiosa na fusão mística e do encantamento fisiológico para desvelar o caráter relacional dos corpos humanos anulado pelo "individualismo anatômico" que começou a surgir com o avanço da dissecação de cadáveres nos séculos XVI e XVII, indicando certa mudança de pensamento que passou a abdicar do caráter relacional originário do humano e que, em favor da autonomia do corpo individual, que tem embasado as posturas sociológicas que concebem a "sociedade" como uma massa de indivíduos só posteriormente e acidentalmente integrados (Cf. PITTA, 2017).
} 
palavra melhor menos prostituída [...]. A teoria do íntimo está dedicada à tentativa de mostrar que todas as ciências do homem aportaram desde sempre suas contribuições para um surrealismo topológico [...] os espaços pelos quais os homens se deixam conter [...]. Para muitas inteligências, pensar nas intimidades domésticas produz espontaneamente uma sensação de enjoo adocicado razão pela qual uma filosofia da doçura é tão inexistente quanto uma elaboração ontológica da esfera íntima (SLOTERDIJK, 2016, p. 81-85) $)^{15}$.

O que Sloterdijk denomina como o íntimo são fundamentalmente espaços interiores partilhados, cossubjetivos e interinteligentes, cujo paradigma microesférico é a placenta. O sangue placentário, o líquido amniótico, o cordão umbilical são todos pensados como "nobjetos", isto é, entidades não confrontativas e não opositoras que se mesclam a um "pré-sujeito" habitando em uma proximidade quase absoluta a acústica uterina. É a partir desses elementos que o nascimento vem abrir a possibilidade inaugural de autonomia, imediatamente rompida pela imersão do recém-chegado nos braços dos pais.

Em outras palavras, o nascimento inaugura uma série de rupturas dos invólucros, jogando o sujeito em novas bolhas e expondo-o a novas relações e experiências. A modernidade, contudo, fez da placenta um mero dejeto obstetrício a ser descartado. Com isso, demostrando que seu projeto consiste, essencialmente, em uma aposta arriscada na transposição da complementação esférica para os meios tecnológicos, dando um passo em falso em direção à chamada antropotécnica biotecnológica.

Tornar-se moderno, nesse sentido, é compreender-se como nunca ter-sido um infante, ou seja, é recusar a infância empreendendo, por meio de uma ascese individual, a busca solitária de seus próprios poderes. Perde-se, assim, o contato direto com a imanência extática do Dasein, passando a existência a se identificar com a coexistência anônima de indivíduo na sociedade massificada. Todo aquele que se ressente, de algum modo, do apoio, da proteção e do cuidado de uma habitação aconchegante em relações esferológicas passa a ser acusado justo de não crescer, de permanecer criança, infante. Um ser incapaz e incapacitado para

\footnotetext{
${ }^{15}$ Com esse argumento, Sloterdijk defende uma retomada do projeto de "ser e espaço" escondido nas entranhas da obra heideggeriana no Ser e tempo- e isso pretende Sloterdijk com toda a trilogia.
} 
enfrentar, por sua conta e risco, as intempéries da mediocridade e da homogeneidade de um exterior desvitalizado impessoal.

Com isso, Sloterdijk desvela nosso mais novo imperativo metanoético: abandonar a infância, sair o mais rápido possível dela. Essa é a condição para sobreviver quando já não se habitam mais esferas de proteção, cada vez mais impossibilitadas de abarcar a humanidade sem entrar em colapso. A recusa da recusa da infância, deixar-se repetir na infância torna-se o principal sintoma de uma vida abandonada à sua própria sorte. Na ótica esférica de Sloterdijk, pensar a infância é pensar a manutenção de esferas íntimas interfaciais, atravessadas por energias "eróticas e miméticas" que desmentem de forma radical a "ilusão de autonomia do sujeito" (SLOTERDIJK, 2016, p. 189), uma vez que a lei fundamental da intersubjetividade é o encantamento recíproco entre os seres humanos.

Sejamos a favor ou contra a tese defendida por Sloterdijk (2016), o fato é que sua esferologia permite repensar as noções clássicas de sujeito, indivíduo, autonomia, consciência, e, sobretudo de infância apreendida aqui como uma tendência essencial à proximidade. A infância, nos diz ele, indica os modos como o humano constrói-se (e interage com) suas relações, dando por meio destas uma forma concreta a si mesmo, ao outro e ao mundo, sendo o infante aquilo que em nós fabrica as bolhas possibilitadoras de uma existência em comum. Essa verdade da infância foi tornada inexprimível para os que não têm mais ouvidos para as "verdades de analfabetos": os experts e os gestores da "socialização mediocrizante das sociedades de massa midiatizadas" (p. 566).

A verdade é simples: a cultura humanista europeia, por sua orientação à objetividade domesticadora do humano é, tanto na abordagem como nos seus resultados, uma atividade voltada para encobrir o êxtase esférico da infância. Esse círculo protetor não é nem meramente fabricado, nem meramente descoberto, mas se arredonda magicamente no umbral entre a construção e a realização de si pelo sujeito. Assim como uma criança com suas bolhas de sabão nos faz ver que a infância é tudo aquilo que nos impele para frente no espaço de possibilidades contido em um círculo de amor. 
É, portanto, legítimo continuar a pensar e a acreditar que tudo o que existe e faz existir está envolto pelo cuidado da/com a infância. Dessa forma, se acolhemos a esferologia como uma provocação necessária para se compreender a infância hoje, é possível integrar e ao mesmo tempo ultrapassar as discussões de Sloterdijk, seja na sua Crítica da razão cínica seja nas suas polêmicas antropotécnicas, abrindo novos caminhos para se pensar a educação da infância a partir da perspectiva diferenciada de imersão do humano em um mundo onde tudo está contido no sopro extático de uma criança.

\section{considerações finais}

A infância sabemos que não se deixa capturar tão facilmente, pois ela não se reduz ao que já fomos capazes de submeter à lógica cada vez mais afiada de nossas práticas e de nossas instituições. A infância escapa-nos à nossa vontade de objetivação, pois ela está sempre em vias de se desviar de todo objetivo predelineado. A infância não é apenas um ponto de ancoragem do poder, mas também seu limite exterior, sua absoluta impotência.

Por isso, a alteridade da infância é algo radical. Nada mais e nada menos do que aquele ponto catastrófico em que se desvanecem nossos desejos de estado e de controle. A presença simultaneamente mágica e enigmática da infância presentifica algo de radical em nossa existência. Aí está a sua vertigem e o seu desafio endereçado às nossas teorias filosóficas e educacionais a exigir, como pede Larrosa (2004, p. 54), gestos de ruptura: olhar mais devagar, escutar mais devagar, pensar mais devagar para destravar o pensamento da infância da cronologia e da temporalidade estática.

Nas últimas décadas, muito se tem falado na necessidade de criar espaços para que a experiência infantil aconteça. Talvez, o problema efetivo seja habitar o espaço que a infância, ela mesma, carrega e projeta na imanência de si mesma. E como diz Sloterdijk (2016, p. 475), para habitar é preciso aprender a ouvir não apenas a voz peculiar do infans, mas, sobretudo aqui que antes do que não fala, nos chama como o mais íntimo em nós. 
Nesse aspecto, ele também retoma o que Hannah Arendt já havia dito, algo tão simples e que todo mundo finge saber: "a educação tem a ver com a natalidade". Mas, diferentemente de Arendt, para Sloterdijk o nascimento de uma criança já é um acontecimento segundo, estando o mistério já presente na clausura materna. A escuta do que aí se passa subverte nossa vontade de poder e de saber. Toda a educação se recoloca aqui, ou seja, na forma em que uma esfera acolhe, nutre e anima quem chega.

Esse gesto radical clama por uma responsabilidade inaudita, pois trazer à existência significa comprometer-se a multiplicar esse lugar primevo e arcaico de nossa chegada, reinventando novos espaços para que a vida prossiga. Esse gesto exige propriamente educadores-formadores, ou seja, não meramente profissionais que entendem de crianças e de educação, mas pessoas dispostas a compartir sua intimidade com seres estranhos, com seres vindos de um estrangeiro além de toda estrangeiridade. Além disso, a formação do infante exige dos educadoresformadores a paciência necessária para suportar as rupturas e os exílios que todo viver encarna.

A partir desse ponto de vista esferológico, uma criança que chega já aparece com a condição de dissolver a solidez de nossos mundos, ao mesmo tempo em que solicita a atitude de criação ético-estética de novas esferas de convivência. Por isso, a infância possa ser pensada aqui como o estado daquele que nascendo salvaguarda as condições paradoxais de permanência e de renovação do mundo face à descontinuidade do tempo.

Dito de outra maneira: o acontecer da infância remete a um mistério inabarcável. A infância não é nunca subordinação do que aparece a nossos conceitos. Como consequência, a verdade da infância não está no que dizemos dela, mas no que ela nos diz no próprio espanto que o acontecimento de sua aparição provoca. Nesse sentido, caberia à Filosofia da educação não produzir novas imagens da infância, mas problematizar suas imagens do que significa pensar, aprender, ensinar, a partir do encontro com a infância. 
Essa condição passa necessariamente pela desconstrução da forma como foram pensados os outros sujeitos e as outras infâncias no campo educacional. Particularmente o pensamento colonizador que tem se legitimado negativizando as múltiplas formas de aparição da infância, sua diferença constitutiva, como algo a ser domesticado, conforma a criança educada aos hábitos normalizadores do adulto civilizado. Esse modo de pensamento sobre os outros persiste nas formas de pensar as crianças e seus coletivos sociais, étnicos, raciais, de gênero, das periferias e dos campos. Disso decorre a necessidade de reaprendermos conjuntamente a nos deixar repetir na infância de nós mesmos e dos outros como exercício seminal para a liberação da potência do pensar.

Nesse exercício de deixar ser a infância, quem sabe, os educadoresformadores possam redescobrir, modos outros de cuidado consigo e com os outros, modos de ampliar sua maneira de lidar ética e politicamente com a infância. Pois é sempre em uma relação de cuidado com a alteridade que o acontecimento da infância pode se concretizar como experiência histórica capaz de incluir efetivamente a diferença trazida pelas crianças.

O acontecimento da infância se dá em uma relação de cuidado com a alteridade. Essa é uma percepção importante, sobretudo nesse momento em que o campo político e acadêmico discute uma compreensão alargada da educação da infância. Talvez, a poética da intimidade, tal como expressa na esferologia descrita por Sloterdijk, nos permita desdobrar as potências imanentes nas relações humanas e extra-humanas que desde uma intimidade ontológica é capaz de transfigurar nossa compreensão da formação da infância, supondo que estejamos dispostos a admitir que não há filosofia ou experiência de pensamento que se realize sem que as paixões se tornem conceitos.

\section{referências}

AGAMBEN. G. Infância e história. Belo Horizonte: UFMG, 2005.

ARAÚJO, R. M. de L. As referências da Pedagogia das Competências. Perspectiva, Florianópolis, v. 22, n. 02, p. 497-524, jul./dez. 2004.

DELEUZE, Gilles. GUATTARI, Félix. Mil Platôs: capitalismo e esquizofrenia, vol. 4. Trad. Suely Rolnik. São Paulo: Ed. 34, 1997. 
FOUCAULT, M. Nascimento da biopolitica. Curso dado no Collège de France (1978-1979). São Paulo: Martins Fontes, 2008.

GADELHA, S. Empresariamento da sociedade e governo da infância pobre. Revista Colombiana de Educación, n. 65, v. 2, Bogotá, Colombia. p. 215-238, 2013.

KOHAN, W. Infância: Entre Educação e Filosofia. Belo Horizonte: Autêntica, 2003.

LARROSA, J. Pedagogia Profana: Danças, Piruetas e mascaradas. Belo Horizonte: Autêntica, 2004.

LEIRNER, P.C. O Estado como fazenda de domesticação. Revista de Antropologia da UFSCar, v.4, n.2, jul.-dez., p. 38-70, 2012.

LEMOS, F. C. S.; GALINDO, D.; NASCIMENTO, M.L. Considerações sobre o empresariamento da vida em políticas públicas para a educação. Revista Barbarói, Santa Cruz do Sul, n.46, p. 6-21, jan./jun., 2016.

PAGNI, P. Infância, Arte de Governo Pedagógico e Cuidado de Si. Revista Educação E Realidade. Porto Alegre, v. 35, n. 3, p. 99-123, set./dez., 2010.

PANSINI, F.; MARIN, A. P. O ingresso de crianças de 6 anos no ensino fundamental: uma pesquisa em Rondônia. Revista Educação e Pesquisa, São Paulo, v. 37, n. 1, p. 87-103, jan./abr., 2011.

PITTA, M. F. Resenha: Esferas I: bolhas, de Peter Sloterdijk Peter Sloterdijk (2016). Esferas I: bolhas (José Oscar de Almeida Marques, Trad.). São Paulo: Estação Liberdade. 578 p. Revista Natureza Humana, São Paulo, v. 19, n. 1, p. 149-158, jan./jul., 2017.

RESENDE, H. (org.). Michel Foucault: o governo da infância. Belo Horizonte: Autêntica, 2015.

SANTOS, L. D. N. dos; BOLZAN, D. P. V. A inclusão de crianças de seis anos na escola obrigatória e sua repercussão na organização do trabalho pedagógico. Disponível em: <http://www.pucpr.br/eventos/educere/educere2008/anais/pdf/955_891.pdf> Acesso em: 07 ago. 2017.

SARMENTO, M. J. As Culturas da Infância nas encruzilhadas da $2^{a}$ Modernidade. 2002. Disponível em: <http://www.cedei.unir.br/submenu_arquivos/761_1.1_u1_as_culturas_na_infancia.pdf $>$ Acesso em: 20 jun. 2007.

SLOTERDIJK, P. Regras para o parque humano: uma resposta à carta de Heidegger sobre o humanismo. São Paulo: Estação Liberdade, 2000.

SLOTERDIJK, P. Has de cambiar tu vida. Sobre antropotécnica. Valencia: Pre-Textos, 2012. SLOTERDIJK, P. Esferas I: Bolhas. São Paulo: Estação Liberdade, 2016

recebido em: 12.12 .2017 aceito em: 25.02.2018 